\title{
A seismological and engineering perspective on the 2016 Central Italy earthquakes
}

\author{
Marco Fasan* \\ Department of Engineering and Architecture, \\ University of Trieste, \\ Piazzale Europa, 1, \\ Trieste I-34127, Italy \\ Email: marcofasan@hotmail.it \\ *Corresponding author

\section{Andrea Magrin}

Department of Mathematics and Geosciences, University of Trieste,

Via E. Weiss, 4 Pal. P,

Trieste I-34128, Italy

and

OGS - Istituto Nazionale di Oceanografia

e di Geofisica Sperimentale,

Dip. C.R.S.,

Via Treviso, 55, Udine I-33100, Italy

Email: andreamagrin@yahoo.it

\section{Claudio Amadio}

Department of Engineering and Architecture, University of Trieste,

Piazzale Europa, 1,

Trieste I-34127, Italy

Email: amadio@units.it

\section{Fabio Romanelli and Franco Vaccari}

Department of Mathematics and Geosciences, University of Trieste,

Via E. Weiss, 4 Pal. P,

Trieste I-34128, Italy

Email: romanel@units.it

Email: vaccari@units.it 


\section{Giuliano F. Panza}

Department of Mathematics and Geosciences, University of Trieste,

Via E. Weiss, 4 Pal. P, Trieste I-34128, Italy

and

Institute of Geophysics,

China Earthquake Administration,

Beijing, China

and

International Seismic Safety Organization (ISSO),

Viale San Francesco, 12, I-64031 Arsita (TE), Italy

and

Accademia Nazionale dei Lincei,

Palazzo Corsini - Via della Lungara, 10 - 00165, Roma

Email: giulianofpanza@fastwebnet.it

Abstract: The strong earthquake (M 6.0-6.2) that hit the central Apennines on August 24, 2016, occurred in one of the most seismically active areas in Italy. Field surveys indicated severe damage in the epicentral area where, in addition to the loss of human life, widespread destruction of cultural heritage and of critical buildings occurred. Using the neo-deterministic seismic hazard assessment (NDSHA), we apply the maximum deterministic seismic input (MDSI) procedure at two of the most relevant sites in the epicentral area, comparing the results with the current Italian building code. After performing an expeditious engineering analysis, we interpret as a possible cause of the reported damages the high seismic vulnerability of the built environment, combined with the source and site effects characterising the seismic input. Therefore, it is important to design and retrofit with appropriate spectral acceleration levels compatible with the possible future scenarios, like the ones provided by MDSI.

Keywords: seismic hazard; response spectrum; neo-deterministic seismic hazard assessment; NDSHA; maximum deterministic seismic input; MDSI; seismic design.

Reference to this paper should be made as follows: Fasan, M., Magrin, A., Amadio, C., Romanelli, F., Vaccari, F. and Panza, G.F. (2016) 'A seismological and engineering perspective on the 2016 Central Italy earthquakes', Int. J. Earthquake and Impact Engineering, Vol. 1, No. 4, pp.395-420.

Biographical notes: Marco Fasan graduated in Structural Engineering at the University of Trieste where he is currently pursuing a $\mathrm{PhD}$ in Earthquake Engineering. His research is focused on performance-based seismic design, seismic hazard assessment and seismic design of steel-concrete composite structures. He is a chartered engineer in Italy.

Andrea Magrin graduated in Physics at the University of Trieste, where he got his $\mathrm{PhD}$ in Geophysics of the Lithosphere and Geodynamics. He was post-doc researcher at Department of Mathematics and Geosciences (2013-2014) and visiting scientist at ICTP ESP-SAND Group (2015). His main research topics are ground motion scenarios and seismic hazard estimation. 
Claudio Amadio is a Full Professor of Structural Engineering at the University of Trieste, Department of Engineering and Architecture. His research topics are: glass, steel and composite structures, timber, earthquake engineering, finite element, numerical modelling, bomb blast. He published more of 220 papers, mostly on peer-reviewed journals.

Fabio Romanelli graduated in Physics at the University of Trieste, where he got his PhD in Geophysics. He is now a researcher in seismology at the Department of Mathematics and Geosciences, and Professor of Seismology, Seismic Risk and Institutions of Physics of the Earth. His main research topics are: seismic and tsunami wave generation and propagation; groundshaking scenarios and seismic hazard estimation, definition of seismic input and estimation of parameters of seismic engineering importance; study of the lithosphere-asthenosphere system.

Franco Vaccari graduated in Geology at the University of Trieste (1986), where he got his $\mathrm{PhD}$ in Geophysics of the Lithosphere and Geodynamics. He was Research Fellow at Gruppo Nazionale per la Difesa dai Terremoti (GNDT) under (CNR) (1990-1999) and at Istituto Nazionale di Geofisica e Vulcanologia (INGV) (2000-2002), collaborator at University of Trieste, Department of Earth Sciences (2003-2006), contract researcher at University of Trieste, Department of Mathematics and Geosciences (2007-2010) and Visiting Scientist at ICTP ESP-SAND Group (1990-2015). His main research interests are: synthetic seismograms; seismic hazard assessment and seismic zoning; development of seismological software. He is author of 120 publications, mostly on international, peer-reviewed journals.

Giuliano F. Panza is a retired Professor of Trieste University. His research topics covered broad multidisciplinary nature of problems as simultaneous use of neo-deterministic seismic hazard assessment (NDSHA) and monitoring of space/time variation of hazard lead to the construction of time/dependent models of particular interest for civil defence. He received EGU Beno Gutenberg medal from Bucharest University Laurea h.c., Medals of Honour from Central European Initiative and NRIAG Egypt, Commemorative Medal from VAST Vietnam, h.prof. from IG/CEA Beijing, Accademia Nazionale dei Lincei, AE, TWAS, RAS and Accademia Nazionale delle Scienze, Knigth OMRI. He is Editor-in-Chief of ESR and Co-Editor of JSEE. In June 2010, he ranks at $\# 4$ by papers in CIENCEWATCH.COM. In the Web of Science ${ }^{\circledR}$, his record includes 109 original articles cited 715 times between January 2000 and May 2010.

\section{Introduction}

On August 24, 2016, at 03:36 (CEST) a strong earthquake hit the central Apennines, one of the most seismically active areas in Italy (http://emidius.mi.ingv.it/CPTI15-DBMI15/). The epicenter is located in an area of complex extensional tectonic setting, near the borders of the Umbria, Marche, Lazio and Abruzzo regions, between the towns of Norcia and Amatrice [see Figure 1(a)]. The moment magnitude was estimated between 6.0 (INGV, 2016) and 6.2 (USGS, 2016), a range well in agreement with standard errors in magnitude estimates. The triggered seismic sequence is concentrated in a narrow band, parallel to the Apennines, bounded to the south by the Aquila sequence of 2009 and to the north by the Valnerina Norcia (1979) and Colfiorito (1997) sequences. 
The analysis of the available strong motion recordings allowed for a preliminary model of the coseismic rupture propagation during the main shock, consistent with the analysis of satellite data (Tinti et al., 2016). The distribution of the dislocation is concentrated in two areas: one, quite shallow near Accumoli and Amatrice, and a deeper one near Norcia. The ground shaking peak values observed at Arquata del Tronto (RQT), Norcia (NRC) and Amatrice (AMT) stations [see Figure 1(b)] suggest a bilateral rupture, along the NW-SE direction, with coherent directivity effects. Field reports indicate severe damage in the epicentral area and, in particular, in the town of Amatrice, where, in addition to the loss of human life, widespread destruction of cultural heritage and of critical buildings is reported (e.g. ReLUIS-INGV Workgroup, 2016) as well.

Figure 1 (a) Map of Italy with the location of the earthquake (black star) and the limits of the area shown in the right panel (black rectangle) (b) Epicentral area with: locations of the accelerometric stations (grey triangles) of Amatrice (AMT), Norcia (NRC) and Arquata del Tronto (RQT), epicenter (grey star), focal mechanism (beach-ball representation) and surface projection of the fault as described in INGV (2016) (grey rectangle)

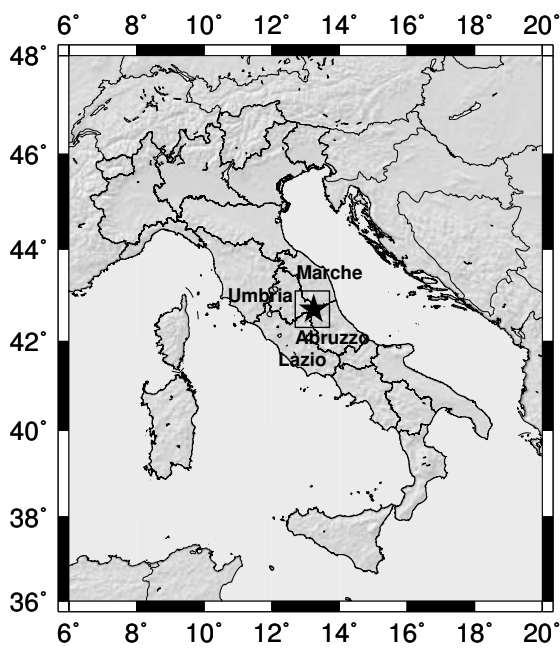

(a)

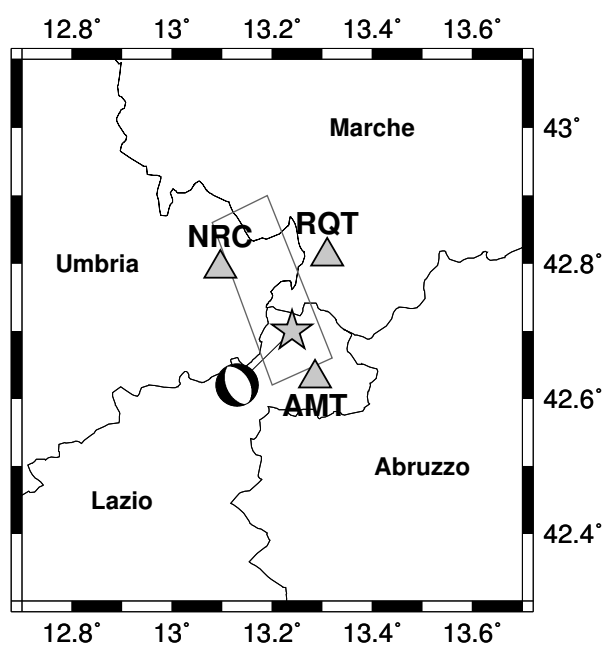

(b)

The applicability of standard probabilistic estimates of seismic hazard (PSHA) is questionable (e.g. Panza et al., 2014 and references therein), even more for historical buildings and monuments. In the study case the problem is made yet more severe and general by source effects that cannot be handled by standard PSHA approaches. A viable alternative, for reliable seismic hazard assessment and structural seismic design, is represented by the use of scenario earthquakes, characterised at least in terms of magnitude, distance and faulting style, simultaneously taking into account the complexity of the source rupturing process. Scenario-based seismic hazard maps are purely based on geophysical and seismotectonic knowledge of a region and, therefore, they may provide an upper bound for the ground motion levels to be expected for most regions of the world.

A scenario-based neo-deterministic seismic hazard assessment (NDSHA) is available nowadays, which considers a wide range of possible seismic sources (including the 
maximum credible earthquake, MCE) as the starting point for deriving scenarios by means of full waveforms modelling, either at national or local scale. The method does not make use of attenuation relations and naturally supplies realistic time series of ground shaking, including reliable estimates of ground displacement readily applicable to seismic isolation techniques.

In Section 2 the most recent version of the NDSHA maps for the Italian territory are illustrated and commented. Based on the neo-deterministic approach, an operational integrated procedure for seismic hazard assessment has been developed that allows for the definition of time dependent scenarios of ground shaking, through the routine updating of intermediate-term middle-range earthquake predictions, performed by means of the algorithms CN and M8S (Peresan et al., 2005). The results from real-time testing of the time-dependent NDSHA scenarios have been recently illustrated with specific reference to the August 24th, 2016 Central Italy earthquake by Peresan et al. (2016).

At local scale, further investigations can be performed taking into account the specific sources and local soil conditions, in order to compute the seismic input (realistic synthetic seismograms) to be used in the engineering analysis of relevant structures, such as historical and strategic buildings. Actually, even if future earthquakes cannot be predicted with 'red alert' precision (e.g. Keilis-Borok and Soloviev, 2003) to warrant evacuation, structural engineers can govern the performance of a building subject to an earthquake of a given intensity through the designing and retrofitting procedures, thus contributing to effective preventive actions. In the light of these considerations, to prevent collapses and human losses, engineers should design and retrofit using an 'upper-bound ground motion'. Using the NDSHA approach, Fasan et al. $(2015,2017)$ proposed a procedure to define this level of seismic input, called 'maximum deterministic seismic input' (MDSI). This approach envelopes uncertainties by means of a wide range of NDSHA simulations rather than quantifying them probabilistically. MDSI does not require the use of the very questionable concepts of reference average life and probability of exceedance.

In Section 3, the results of the application of the MDSI procedure to two of the most relevant sites in the epicentral area (i.e. Amatrice and Norcia) are compared with the spectral shapes from the Italian building code NTC08, effective since 2008 (NTC08, 2008).

In Section 4, after a brief description of the main types of damage caused by the event at selected sites, a possible explanation of them is given performing a simplified analysis of the lateral resistances of the masonry building stock and of the seismological characteristics of the recorded signals. Finally, using the same simplified approach, it is shown what might happen in future scenarios compatible with the seismic potential of the area.

\section{Broadband neo-deterministic seismic zoning at regional scale}

The most recent version of the NDSHA maps for the Italian territory are shown and briefly discussed here: the NDSHA procedure, described in detail in Panza et al. (2001, 2012), is summarised, the upgrades in the seismograms computation are described and the new maps are commented.

In NDSHA at regional scale, the sources are defined from the available information about the space distribution of large size earthquakes, taking into account the seismic history (historical and instrumental earthquake catalogues), seismotectonics (seismogenic 
zones) and morphostructural analysis (seismogenic nodes). The definition of the space distribution of seismicity relies upon the largest events reported in the earthquake catalogue at different sites, as follows. Earthquake epicenters reported in the catalogue are grouped into a grid formed by $0.2^{\circ} \times 0.2^{\circ}$ cells and to each cell the maximum magnitude, recorded within it, is assigned. Then a smoothing procedure is applied to account for the spatial uncertainty in epicenters' location and for the source extension. A centered smoothing window with a radius of three cells is considered and the maximum value found in the window is assigned to the central cell. After smoothing, only the cells located within the seismogenic zones and the seismogenic nodes are retained. The magnitude of the chosen cells is defined as the maximum between a lower bound and the magnitude defined by the smoothing procedure. The lower bound for magnitude inside the seismogenic zones is 5, that is conventionally (D'Amico et al., 1999) taken as the lower bound for the magnitude of damaging earthquakes. The lower bound of magnitude inside the seismogenic nodes is the magnitude threshold identified for that node by the morphostructural analysis. A double-couple point source is centered in each cell, with a focal mechanism consistent with the properties of the corresponding seismogenic zone or node. Source depth is taken as a function of magnitude to account for the magnitude-depth relationship demonstrated in the statistical properties of earthquake occurrences (Caputo et al., 1973; Molchan et al., 1997; Doglioni, 2016).

To define the physical properties of the source-site paths, the territory is divided into a set of polygons, each characterised by a structural model composed of flat, anelastic layers that represent the average lithosphere properties at regional scale. Synthetic seismograms are then computed by the modal summation technique (MS henceforth) considering the average structural model associated to the regional polygon that includes the site. Sites are considered at the nodes of a grid with step $0.2^{\circ} \times 0.2^{\circ}$ which covers the national territory and is staggered by $0.1^{\circ}$ with respect to the grid used to group and select the epicenters. As shown in Panza et al. (2012), the source can be treated as size scaled point source (SSPS) or as size and time scaled point source (STSPS). The STSPS model (Parvez et al., 2011) is based on an extended source model provided by the PULSYN06 algorithm (Gusev, 2011) and takes into account a reference scaling law for source spectra (SLSS).

The starting point of the upgrade is represented by the maps obtained from the seismograms computed with cut-off frequency of $10 \mathrm{~Hz}$ adopting the structural models of Brandmayr et al. (2010), i.e. 'model 6' of Panza et al. (2012). The definition of earthquake sources is based on the same input of 'model 6': earthquake catalogue CPTI04 (Gasperini et al., 2004), integrated with the catalogues for Slovenia and Croatia (Živčić et al., 2000; Markušić et al., 2000), the ZS9 seismogenic zoning (Meletti and Valensise, 2004) and the seismogenic nodes identified by Gorshkov et al. (2002, 2004, 2009). It is important to highlight that these new maps are computed starting from information contained in earlier publications deliberately excluding the evidence from this last earthquake.

Further upgrades to the methodology, described in Fasan et al. (2015) and Magrin et al. (2016), are the use of the discrete wave number technique (henceforth named DWN) for short paths, the use of a new SLSS and of multiple stochastic realisations of the source model (slip distribution and rupturing velocity). In addition to maps of peak ground displacement (PGD) and peak ground velocity (PGV) (Figure 2), maps of spectral acceleration (SA), more significant than peak ground acceleration (PGA) for the engineering analyses, are given in Figure 3 (5\% damping at periods 0.2 and $1 \mathrm{~s}$ ). 
The MS technique is computationally very fast and provides an adequately precise simulation of ground motion in the far field, but it is not appropriate for the generation of hazard scenarios in near source and near field condition. The limit is easily bypassed using the discrete wavenumber technique (DWN) in the implementation of Pavlov (2009), which gives the full wave field, including all body waves and near field. Since the computational cost of DWN increases with epicentral distance-source depth ratio, a good compromise between accuracy and CPU time is to use DWN for computations at epicentral distances less than $20 \mathrm{~km}$ and MS for larger distances.

Figure 2 (a) Maps of the median of the PGD (left) and PGV (right) computed considering 100 different random realisations of the earthquake source model (b) Maps of ratios between the values in the top of the figure and the corresponding ones of 'model 6' of Panza et al. (2012)
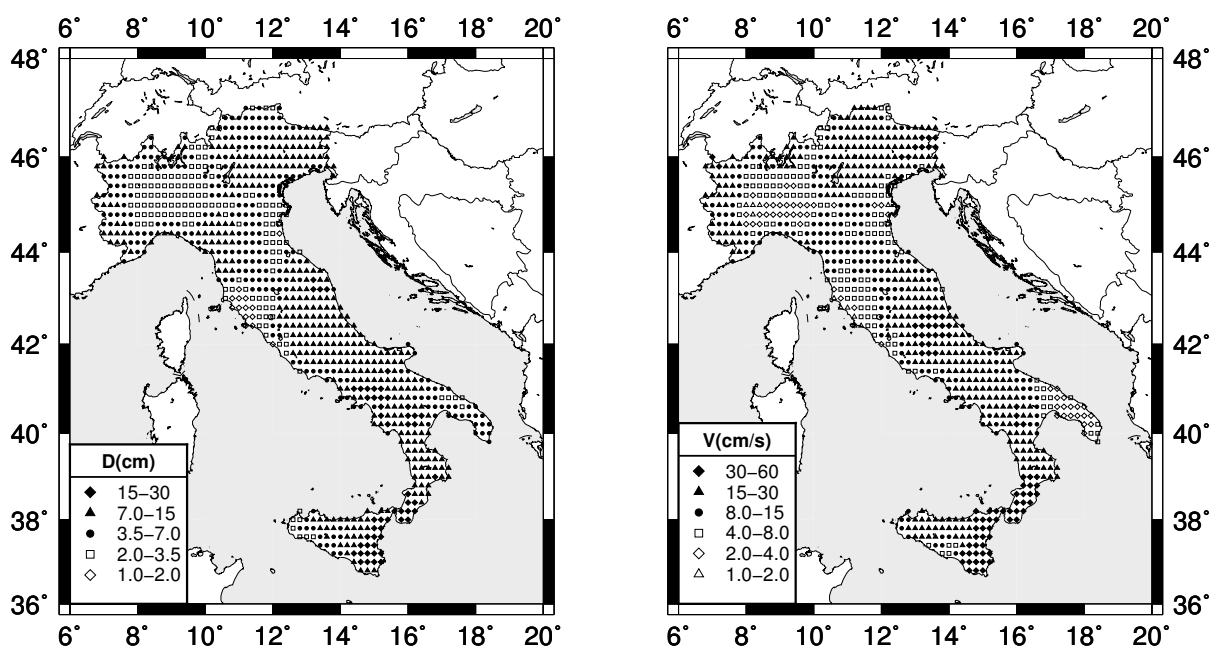

(a)
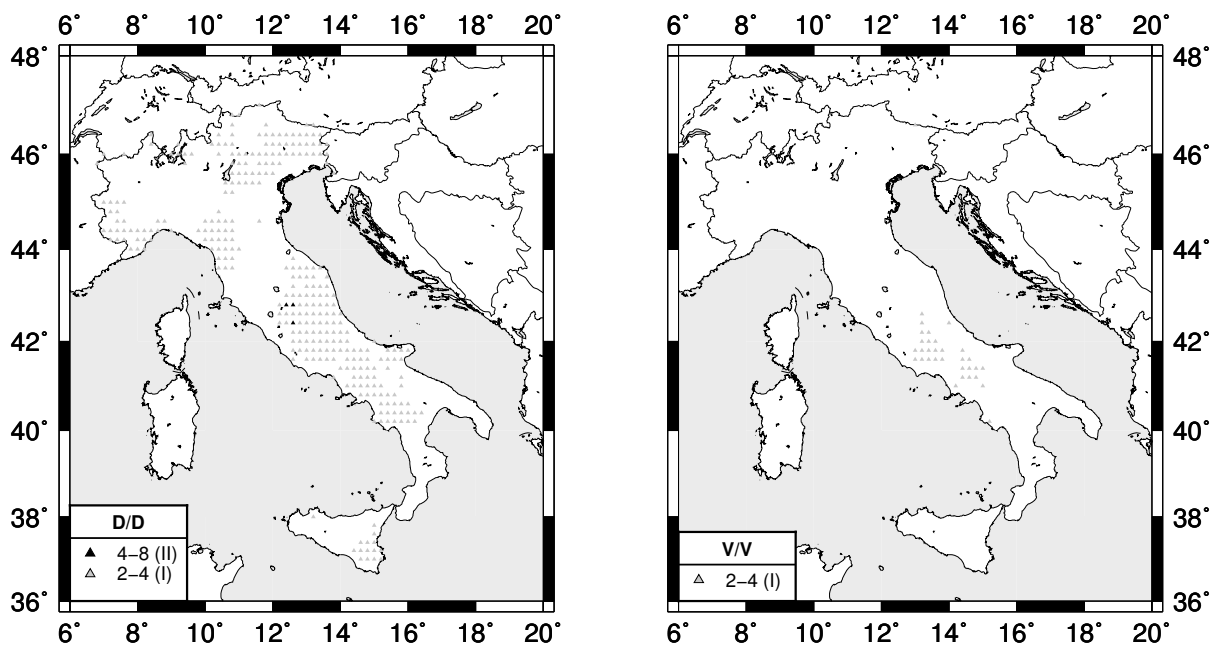

(b) 
Figure 3 Maps of the median of the maximum between the SA computed from NS and EW seismograms with $5 \%$ of damping at (a) $\mathrm{T}=0.2 \mathrm{~s}$ and at (b) $\mathrm{T}=1 \mathrm{~s}$ computed from 100 different random realisations of the earthquake source model

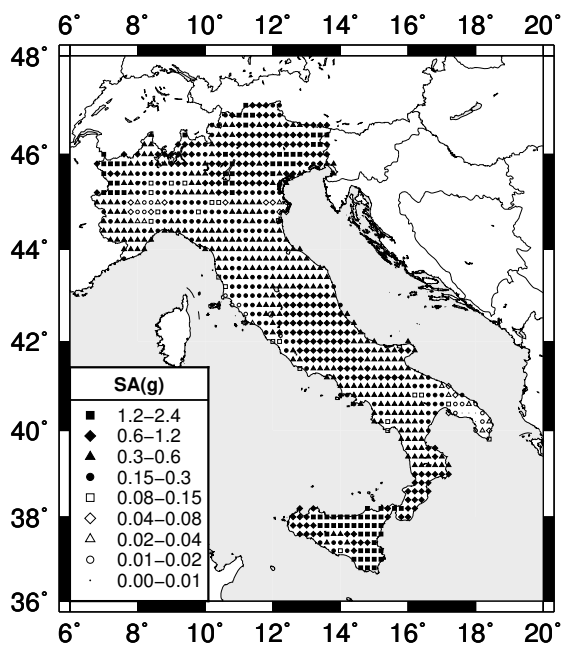

(a)

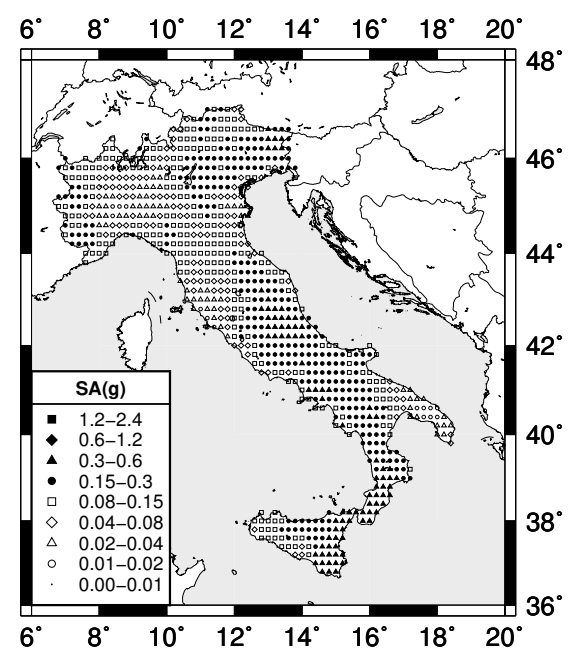

(b)

The SLSS used in Panza et al. (2012) was the one of Gusev (1983) that reasonably represents seismic source data at a global scale, as successfully tested in particular by Boore (1986). Magrin et al. (2016) updated the SLSS focusing on the Italian region. The new SLSS, named G11D spectral family, is defined along the lines suggested by the comparison between the results of national scale NDSHA modelling and existing ground motion predictive equations (GMPE). G11D has been tested on a set of observed values, partially independent on the dataset used to derive the GMPE (Magrin et al., 2016). The used data are up to the end of 2013, so as the other input of these new maps they do not take into account the data from this last earthquake.

The use of source spectra computed by PULSYN06 (Gusev, 2011) in the far source approximation, introduces a stochastic element in NDSHA and its relevance must be evaluated, to enable realistic estimates of seismic hazard and their uncertainty. For this purpose the procedure described in Fasan et al. (2015) has been applied. For each source-site path synthetic seismograms are computed with 100 realisations of the same stochastic source model used in Magrin et al. (2016). For each path, the ground motion parameters computed from the different realisations are gathered and their distribution is determined. Finally, for each site, the median of these distributions is compared and the path that gives the maximum median is chosen. The procedure is repeated for each selected ground motion parameter (e.g. PGD and PGV) and for SA at each period (e.g. $0.2 \mathrm{~s}$ and $1.0 \mathrm{~s}$ ). PGV and PGD values shown in the maps are the peaks of the resultant between the two horizontal components, whereas the SA values are the maximum between the SA computed from the two horizontal accelerograms (NS and EW). This choice allows us a direct comparison between SA, computed here with NDSHA, and the SA from NTC08.

The maps shown in Figure 2 are compared with those computed with $10 \mathrm{~Hz}$ cutoff frequency in Panza et al. (2012) using the same set of structural models (model 6). The 
values in the new maps (Figure 2) are higher than the values in the old ones, especially for displacement, whereas velocity values are fairly consistent with earlier estimations (Panza et al., 2012). These simulations provide a preliminary evaluation of the uncertainty in the hazard maps due to the unavoidable random component of each earthquake source. At each site we considered the distribution of the peak values from the different random realizations of the source model: the standard deviation varies between $10 \%$ and $20 \%$ of the average for most of the Italian territory.

\section{The MDSI spectra procedure}

Fasan et al. $(2015,2017)$ proposed a procedure to define MDSI, that is the 'upper-bound ground motion' that engineers should adopt for design and retrofitting using the NDSHA approach. The seismic input is defined at a given site carrying out the analysis at two possible levels of detail. The first one (regional scale analysis, RSA) provides the MDSI as a response spectrum at the bedrock (MDSI $\mathrm{BD}_{\mathrm{BD}}$ ), similarly to what is proposed by the codes. The second one (site specific analysis) takes the site and source effects into account, providing a site specific seismic input $\left(\right.$ MDSI $\left._{S S}\right)$. MDSI can be defined either as a response spectrum or as a set of seismograms, and it is free from arbitrary choices like reference average life and probability of exceedance.

The RSA is given by the NDSHA at regional scale, as described in Section 3. At each site and at each period, SA values computed from different scenarios are compared and the maximum is chosen. That means that the $\mathrm{MDSI}_{\mathrm{BD}}$ at different periods can originate from different scenarios (in terms of magnitude, epicentral distance, earthquake focal mechanism). In this way RSA allows for the identification of the sources responsible for the highest hazard at the bedrock at the different periods. Because of the semi-stochastic nature of the source model (Gusev, 2011), each scenario provides a distribution of possible values and the MDSI $_{\mathrm{BD}}$ can be chosen among different levels of SA. MDSI $\mathrm{BD}_{\mathrm{BD}}$ should be set equal to their envelope (Fasan et al., 2017). Alternatively, at the cost of reducing safety level, $\mathrm{MDSI}_{\mathrm{BD}}$ could be arbitrarily set equal to 84th percentile, as suggested by ASCE 7 (ASCE, 2013) for the standard deterministic analysis, or equal to the median as done by several codes for the probabilistic analysis [e.g. Italian Building Code $($ NTC08, 2008)], or equal to the 95th percentile, as done by codes for dead loads. A visual description of the procedure is shown in Figure 4.

Fasan et al. $(2015,2017)$ propose to associate MDSI SS $_{\text {sith }}$ the worst structural performance acceptable for a building, called target performance level (TPL). The importance of the structure (risk category) is taken into account by changing the structural performance level to be checked (e.g. collapse prevention for a standard residential building or operational level for hospitals), and not the seismic input.

In order to improve the design process, the performance-based seismic design (PBSD) philosophy suggests additional performance checks. These performance levels are called lower performance levels (LPLs) and, even if they are generally associated with a less severe seismic input, for some structures they may be more conservative with respect to the verification of the TPL (e.g. interstorey drift in steel moment resisting frames). The seismic input level associated to the LPLs can be found either using probabilistic values or reducing the MDSI sS spectral accelerations. 
Figure 4 Description of the MDSI definition procedure

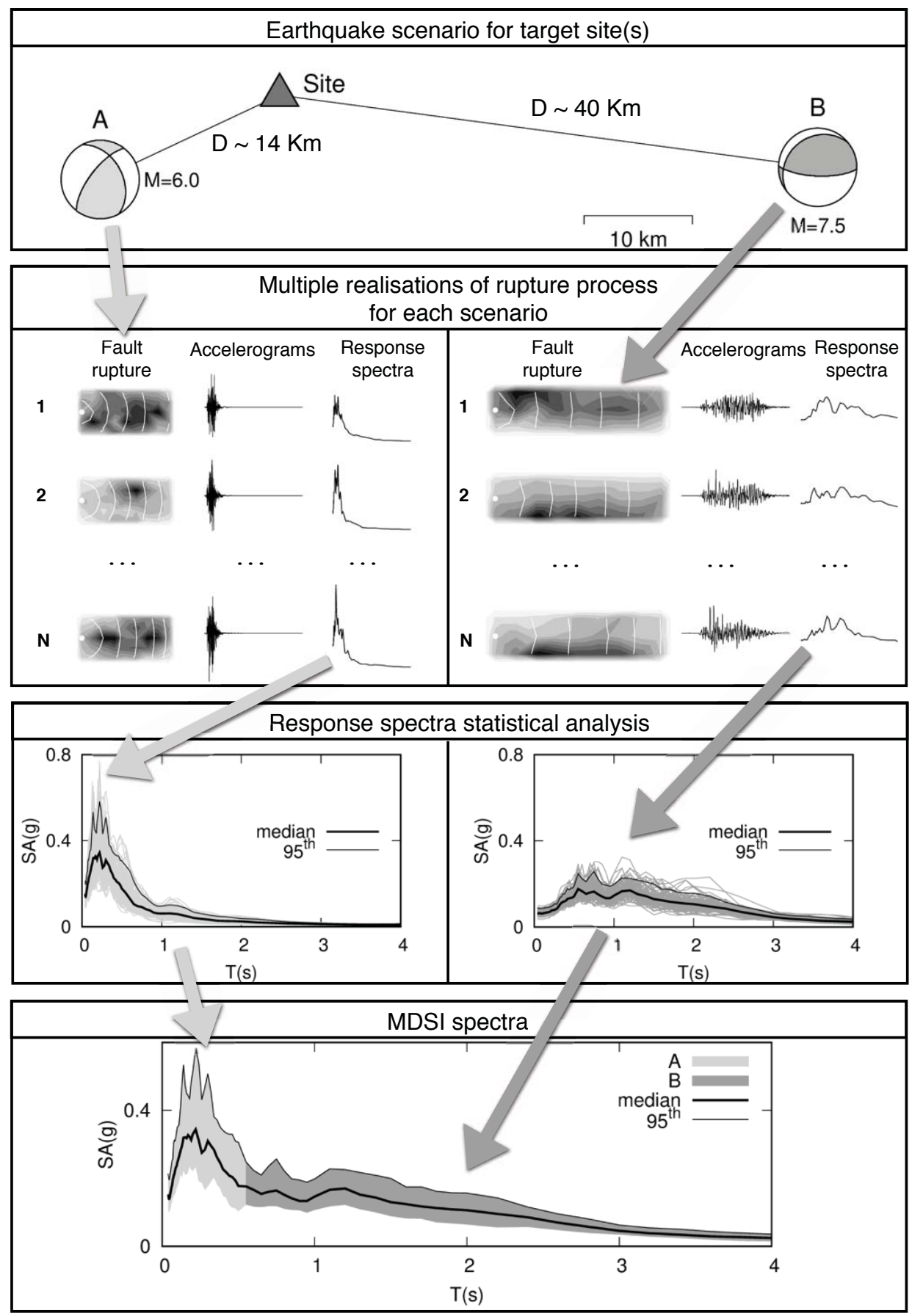


Figure 5 Maps of the epicentral area (the same shown in Figure 1), (a) locations of the epicenter (grey star) and of the accelerometric stations considered in Sections 3 (grey triangles) $[(\mathrm{b}),(\mathrm{c})]$ details of SA maps of Figure 3

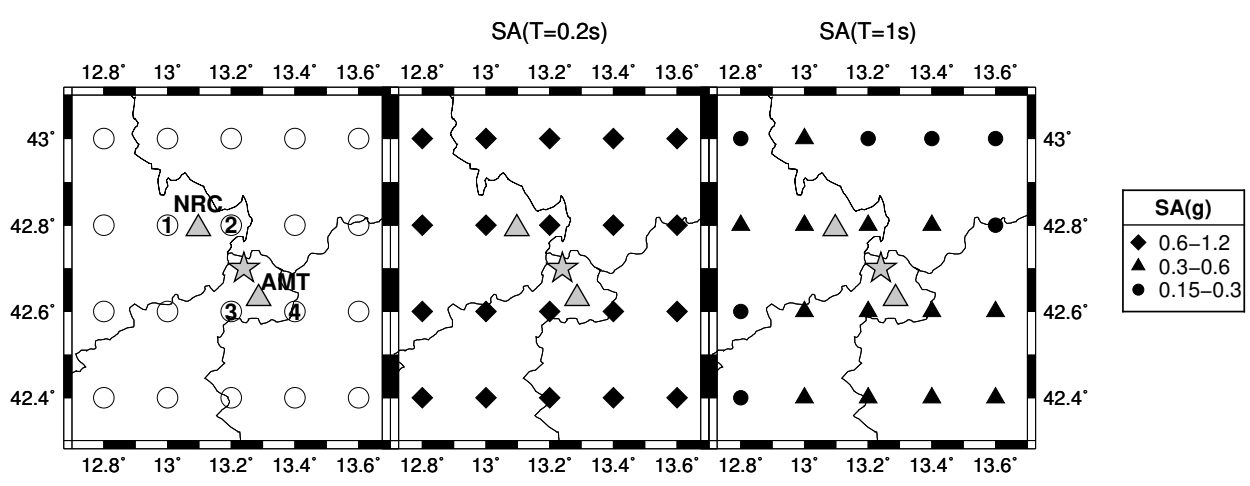

(a)

(b)

(c)

Notes: Grey circles show grid points where NDSHA computations at regional scale are performed; numbers within grey circles identify the four sites where the MDSI ${ }_{B D}$ of Figure 6 have been computed.

\subsection{The 2016 Central Italy earthquake: application of MDSI spectra, comparison with building code and parametric studies in the epicentral} area

The results of the MDSI procedure applied to the epicentral area of 2016 Central Italy earthquake are discussed here. The $\mathrm{MDSI}_{\mathrm{BD}}$ are computed starting from information described in Section 2, i.e. deliberately excluding the evidence from this last earthquake. We enhance the computations shown in Section 2 by increasing the number of realisations of source spectra to 300 and we extract the $\mathrm{MDSI}_{\mathrm{BD}}$ at the grid points nearest to the accelerometric stations of RAN network (Rete Accelerometrica Nazionale - National Accelerometric Network, Italian Civil Protection Department, Presidency of the Council of Ministers - http://ran.protezionecivile.it/) that are located nearest to the epicenter (AMT and NRC) (Figure 5). In the following analyses we do not include RQT station, for which the NS component is not available in the data base. In Figure 6, we compare the $\mathrm{MDSI}_{\mathrm{BD}}$ with the spectra derived from $\mathrm{NTC}$. The $\mathrm{MDSI}_{\mathrm{BD}}$ is comparable with the NTC08 spectra for a 'return period' ${ }^{1}$ of 2,475 years, but the NTC08 spectral values are higher than the $\mathrm{MDSI}_{\mathrm{BD}}$ for periods longer than $2 \mathrm{~s}$. The sources that control $\mathrm{MDSI}_{\mathrm{BD}}$ are those located at the grid points nearest to the sites (epicentral distances around $13 \mathrm{~km}$ ) and their magnitude is between 6.8 and $7.0^{2}$.

The two stations are not on rock: both are on soil class $B\left(V_{S, 30}\right.$ between 360 and $800 \mathrm{~m} / \mathrm{s}$, as defined by NTC08). To compare the results of the computations with the observed ground motion the specific site conditions must be considered. The average structural model representative of the NRC station site is based on the models proposed by Bohm et al. (2011) and Bindi et al. (2011) and it has been used to perform at the nearest site to NRC station (site 1 in Figure 5) the same computations made long before the study event, at bedrock, as described in Section 2. The comparison between the bedrock SA and the local structure SA (Figure 7) shows large effects, especially around $1 \mathrm{~s}$. The maximum horizontal SA from the seismogram of NRC station (downloaded 
from the RAN website) is compared with the design spectra of NTC08 and with MDSI SS $_{\text {S }}$ in Figure 8. The observed SA is comparable with the NTC08 spectrum with a 'return period' of 475 years except for the periods between $0.1 \mathrm{~s}$ and $0.3 \mathrm{~s}$ where it reaches $1.8 \mathrm{~g}$. The observed SA exceeds the NTC08 spectrum with a 'return period' of 2,475 years too.

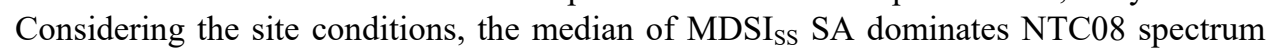
with 'return period' of 2,475 years, precisely in the period ranges $(0.1-0.4) \mathrm{s}$ and $(0.7-1.6) \mathrm{s}$.

Figure 6 Comparison between NTC08 for two 'return period' values (475 and 2,475 years) and MDSI $_{B D}$ (grey areas correspond to the values between median and 95th percentile) for the sites of Figure 5
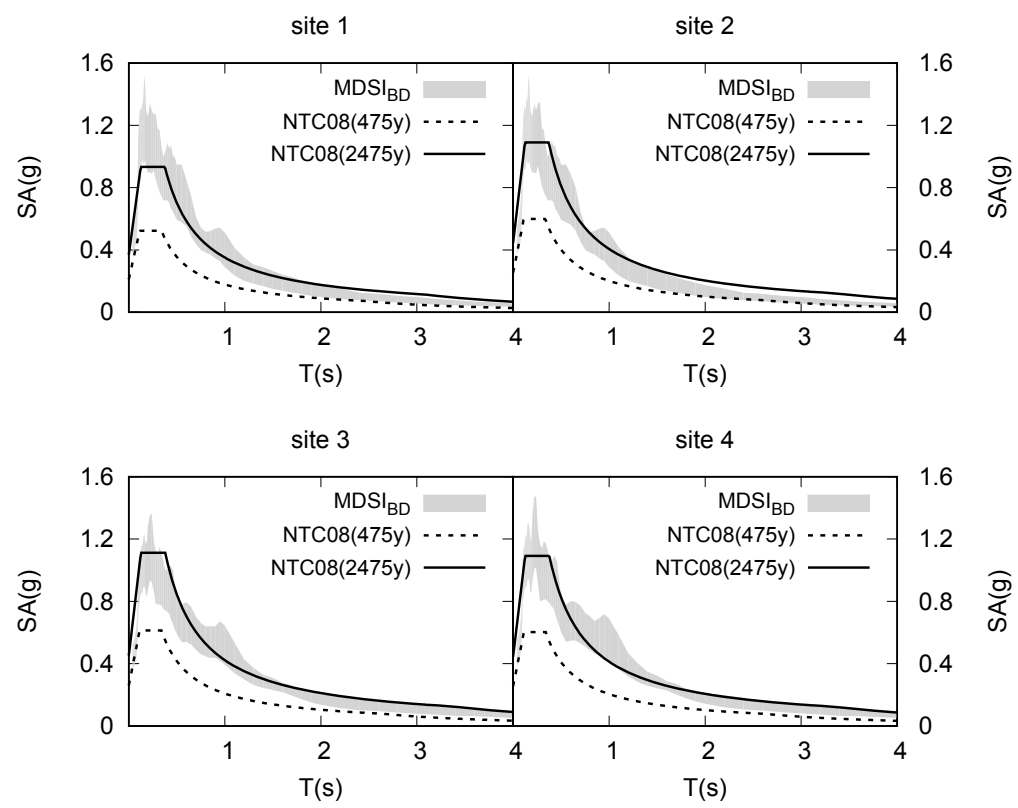

Figure 7 Comparison between MDSI computed with the local structure (MDSI ${ }_{S S}$ ) and MDSI $_{\mathrm{BD}}$ at site 1 (see Figure 5)

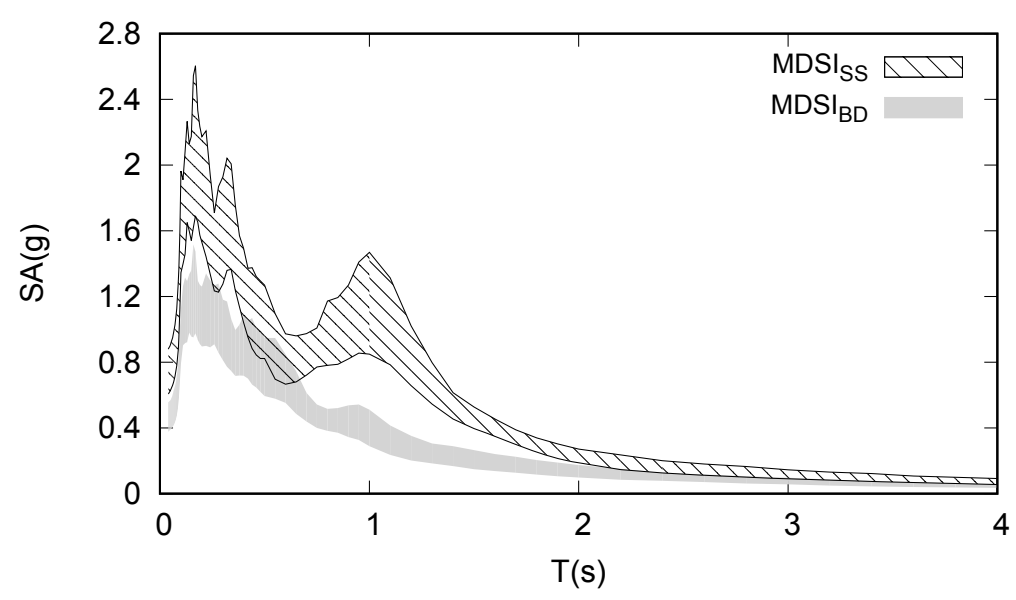


Figure 8 Comparison between observed SA at NRC station (grey line) (envelope between NS and EW components), NTC08 spectrum for soil B at the same site (dark lines) and local

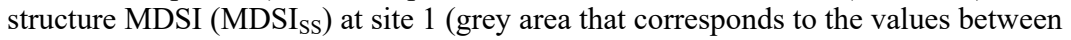
median and 95th percentile)

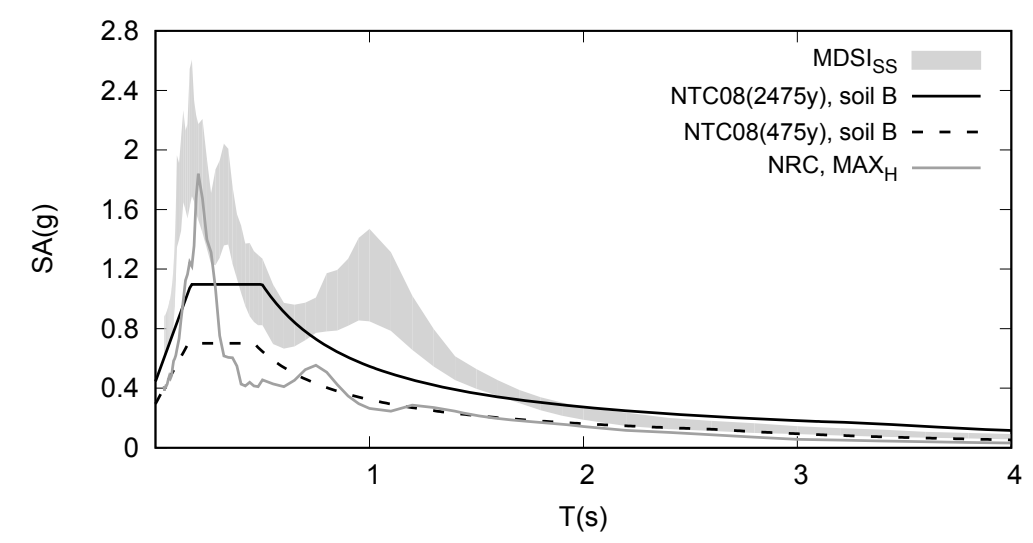

\section{Damage to buildings and engineering aspects}

The places most affected by the Central Italy earthquake are the towns of Amatrice, Accumoli and Arquata del Tronto, all located within a radius of about $15 \mathrm{~km}$ from the epicenter. The architectural heritage of the area is composed mainly of old unreinforced masonry buildings with two or three floors, some of which date back to the 13th century, and infilled reinforced concrete buildings with a number of floors varying between two and five, built since the early fifties. Observed damage is consistent with experiences gained from earlier earthquakes occurred in the area (e.g. D'Ayala and Paganoni, 2011; Ricci et al., 2011).

\subsection{Masonry buildings}

In the places affected by the earthquake, the main construction technique used for unreinforced masonry buildings consists of double wythe load-bearing walls, built with irregular stones (generally called 'a sacco') (Figure 9). Usually there is lack of an adequate connection between the two wythes and the space between them is filled with smaller rubble masonry. These buildings are characterised by flexible timber diaphragms and poor wall-to-wall and wall-to-floor connections. The seismic vulnerability of this type of buildings is therefore very high because of their poor resistance to lateral loads.

Observed damage varies from a state of widespread cracking to global collapse depending on the quality of the masonry, the plan layout and structural irregularities (Figures 10 and 11). The majority of failures consist in an out-of-plane overturning of the perimeter wall due to ineffective connection to diaphragms and orthogonal walls (Figure 10). Buildings with a better degree of connection of the walls exhibited in-plane behaviour. Observed damage due to in-plane behaviour are mainly diagonal and vertical cracks (shear failure and rocking) of the vertical and horizontal masonry panels between openings (piers and spandrels) [Figure 11(b)]. Several ancient buildings in which the original timber floors and roofs were replaced with reinforced concrete elements have 
collapsed partially or totally. The addition of reinforced concrete (RC) diaphragms does not seem to have been supported by effective connections nor by improvements of the quality of existing masonry walls (for example with mortar injections). Without these measures the insertion of concrete elements has, in fact, only increased the mass of the buildings making them even more vulnerable.

Figure 9 Double wythe masonry wall (Accumoli)
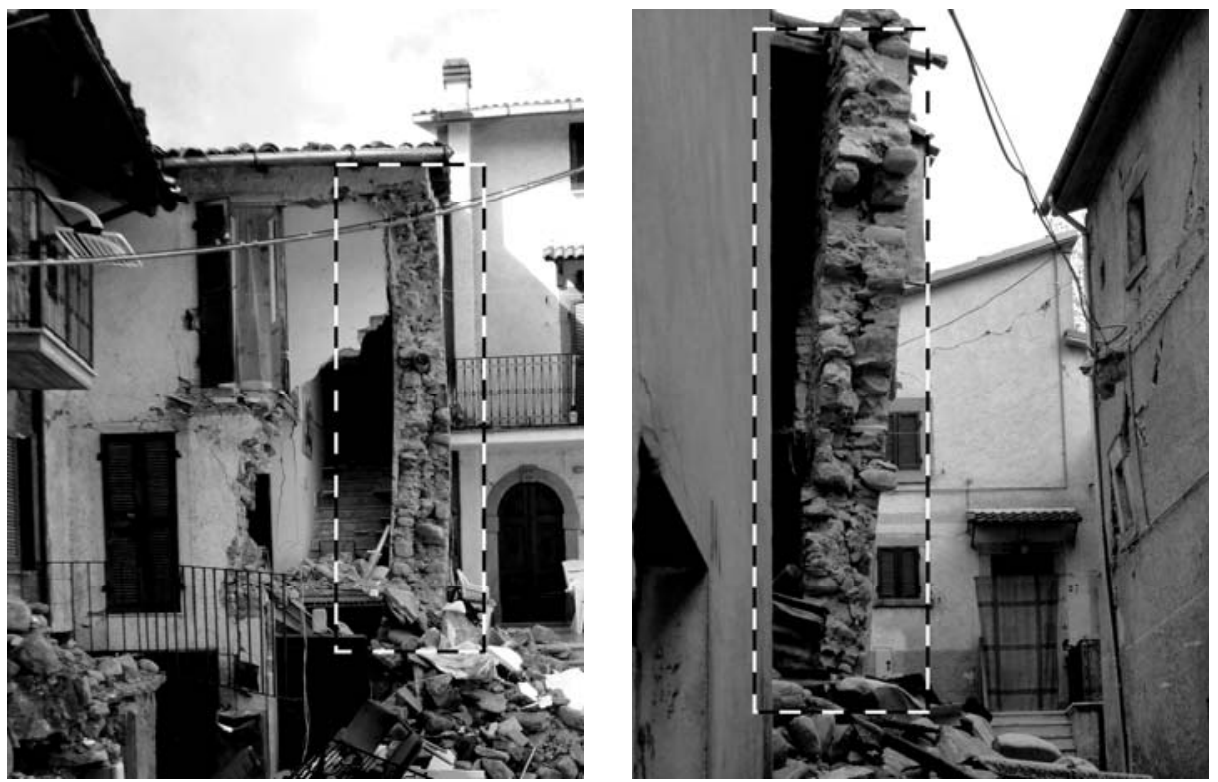

Figure 10 Out-of-plane overturning of the perimeter wall (Accumoli)
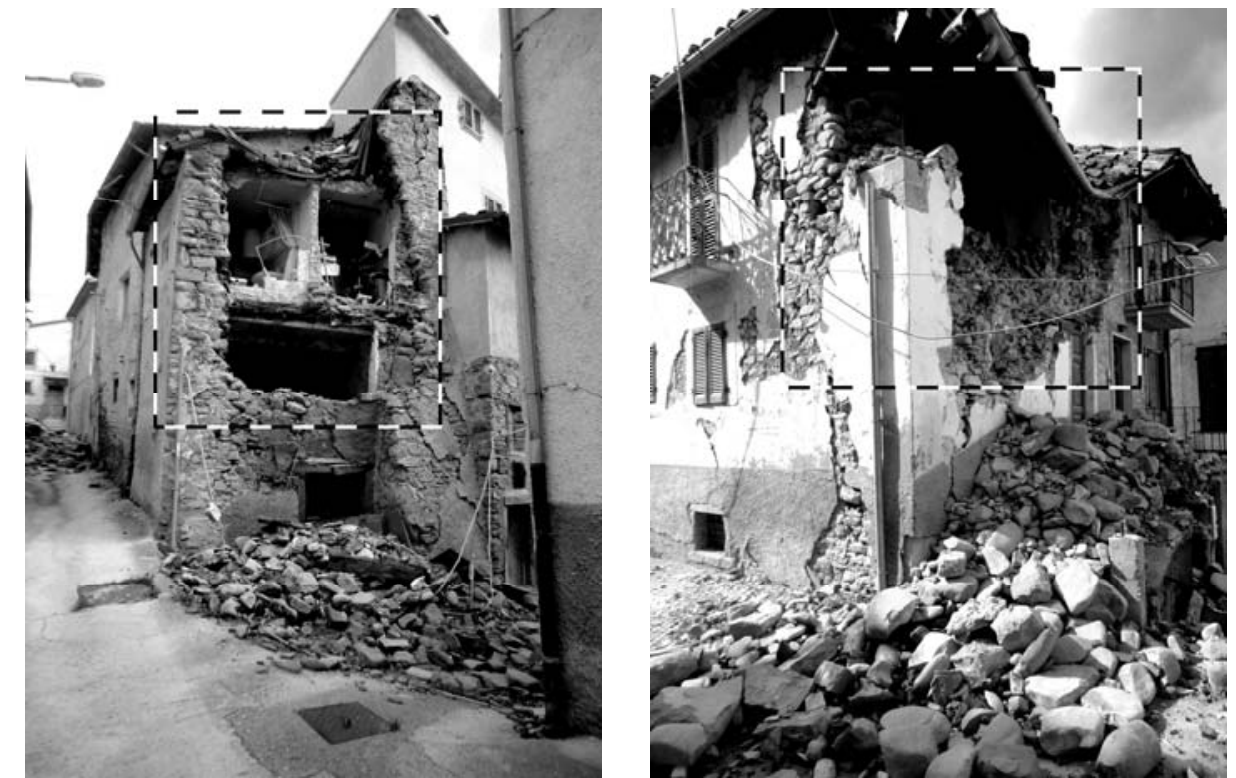
Figure 11 Complete collapse of (a) masonry wall and (b) diagonal cracking due to shear failure (Amatrice)

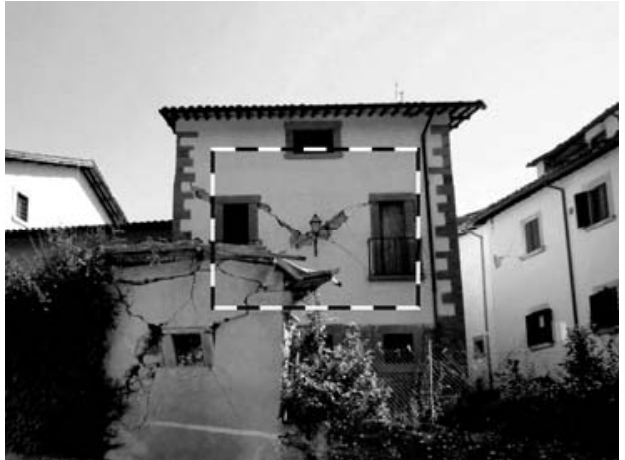

(a)

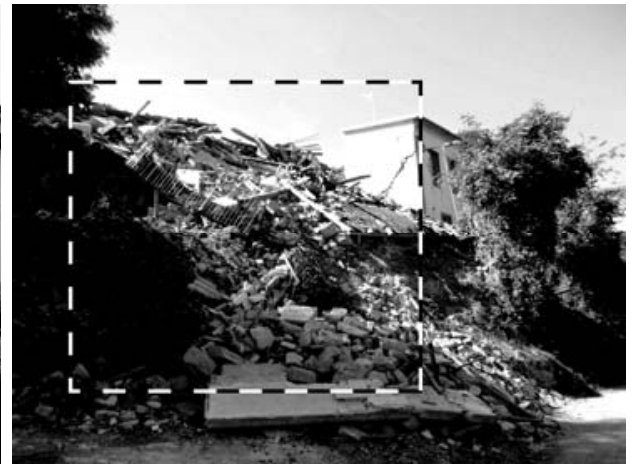

(b)

Among the cities nearby the epicenter, the town of Norcia, at an epicentral distance of about $15 \mathrm{~km}$, exhibited a very good seismic behaviour and little damage has been recorded. Norcia underwent an extensive retrofit of the buildings after the 1997 Umbria-Marche earthquake. The out-of-plane mechanism, which can resist to a really slow acceleration, was minimised inserting steel ties, properly connected ring beams and stiffening the diaphragms. These construction details allowed the masonry walls to exhibit an in-plane behaviour and to increase their resistance. Moreover, the quality of the masonry walls was improved (e.g. with mortar injections) in several buildings.

\subsection{Reinforced concrete buildings}

The RC buildings in the area affected by the earthquake are mainly framed structures with masonry infills (perforated or hollow blocks). It is rare the presence of shear walls. The heights fall in the low-to-mid range and usually do not exceed four storeys.

Most of the concrete structures were designed in an era where seismic details were not prescribed by the codes, hence without the application of the weak beam/strong column criterion, using smooth rebars and not adequately spaced stirrups. Usually the influence of the masonry infills on the global behaviour was neglected. Often there is absence of stirrups in the nodal zone.

Several damage occurred to non-structural elements, in particular infills and internal partitions. Several external infills suffered widespread cracking in their plane, due to the lack of a properly designed gap between them and the load bearing frame. In several cases infills were ejected due to out-of-plane failure because there was not an effective connection between them and the RC frame [Figure 12(a)].

Several are the cases where brittle failures caused storey mechanisms (soft storey), in particular after the out-of-plane ejection of the walls which caused an abrupt variation of stiffness [Figure 12(b)].

Damage to structural elements consist mainly of brittle failures of columns and beamto-column joints due to a low shear resistance (too spaced stirrups, small diameter, lack of stirrups in the nodal zone) and to the additional shear transmitted by the rigidly connected infills (Figure 13). 
Figure 12 (a) Ejection of the infills (Arquata del Tronto) and (b) soft storey mechanism (Amatrice)

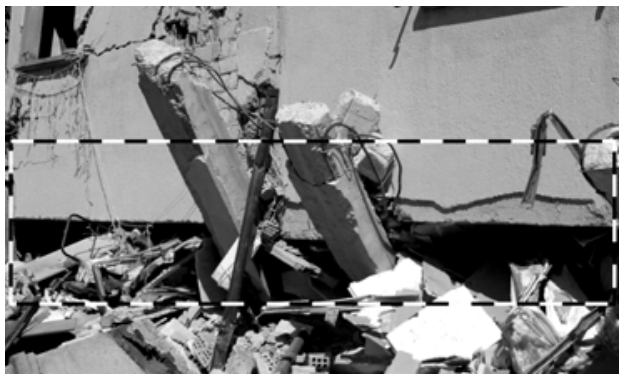

(a)

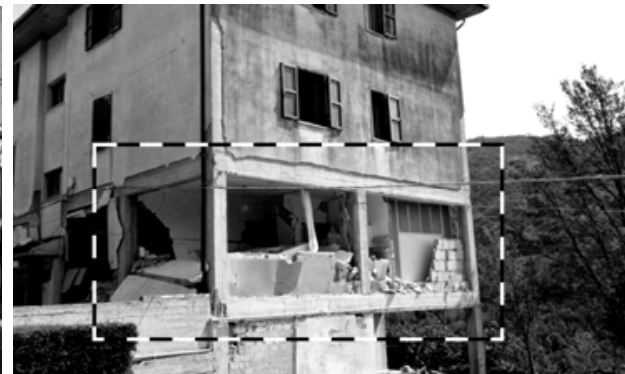

(b)

Source: Modified from ReLUIS (2016)

Figure 13 Beam-to-column joint failure due to lack of stirrups [(a) Amatrice and (b) Arquata del Tronto]

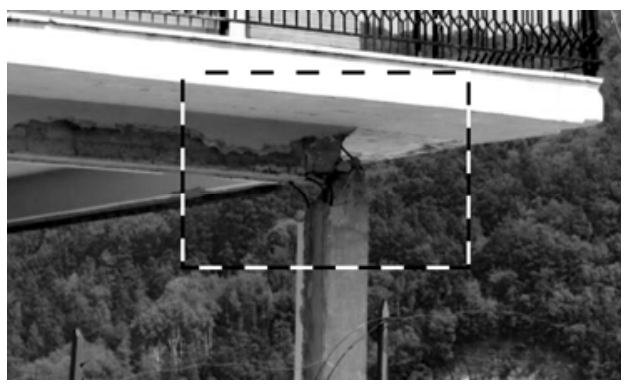

(a)

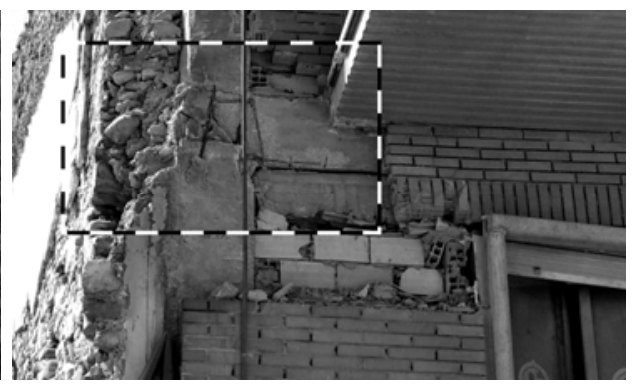

(b)

Source: Modified from ReLUIS (2016)

\subsection{Interpretation of the building heritage seismic behaviour in Amatrice and Norcia}

Almost all damage was recorded in buildings designed without seismic construction details, hence suffering from no or low ductility. In fact, although the first anti-seismic code in Italy which requires the application of horizontal seismic loads dates back to 1908 and the places affected by the earthquake are classified as seismic zone since 1930, only in 2003 the Italian seismic code introduced precise indications regarding the construction details required to ensure high ductility.

Figure 14 shows, for the stations of Amatrice (AMT) and Norcia (NRC), the comparison between the recorded elastic response spectrum $\left(\mathrm{MAX}_{\mathrm{H}}-\right.$ envelope between NS and EW components), the elastic response spectrum used for the design of standard residential building as per the latest Italian seismic code ('return period' of 475 years) and the maximum elastic response spectrum given by the standard ('return period' of 2475 years). As it can be seen, in the typical range of periods of masonry structures $(0.25 \div 0.4 \mathrm{~s})$, the shaking generated by the earthquake exceeded the levels of spectral acceleration set by the latest standard (NTC08, 2008). If one adds to this the fact that the seismic action levels, from 1908 up to now, have always been increased at each 
regulatory update, it can easily be concluded that the occurred damage is due to a poor seismic design process, mostly due to the underestimation of the actual seismic input.

As a rule, reinforced concrete buildings behaved better than masonry buildings since the earthquake excited mainly short periods. Figure 14 shows that in the standard range of periods of reinforced concrete structures $(0.4 \div 1.0 \mathrm{~s})$ the recorded spectral accelerations are lower than the code spectral acceleration for the town of Amatrice whereas they are almost identical in the case of Norcia.

Figure 14 Comparison between the recorded elastic response spectra (envelope between NS and EW components) and the ones given by NTC08 ('return period' of 475 and 2,475 years) for the sites of (a) Amatrice and (b) Norcia

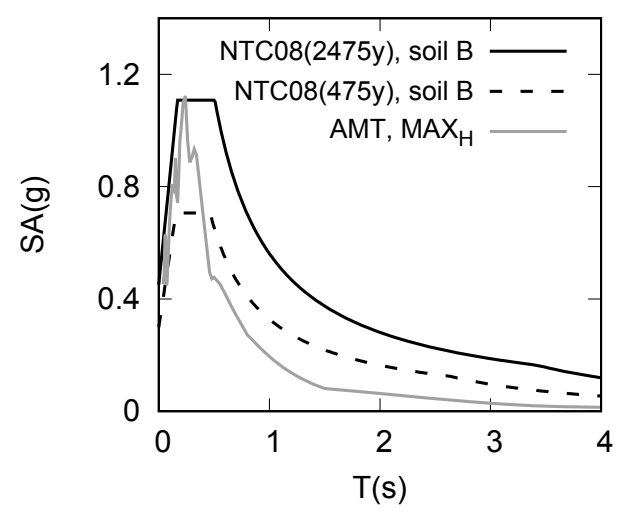

(a)

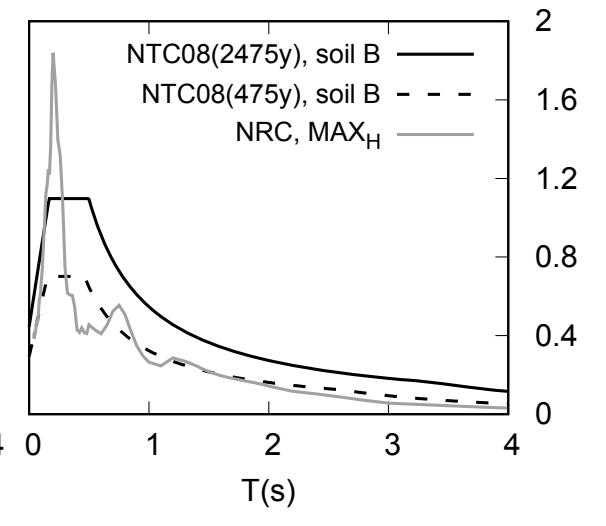

(b)

Table 1 Main characteristics of the Amatrice (AMT) and Norcia (NRC) accelerograms

\begin{tabular}{lllllllc}
\hline Record & Component & $\begin{array}{c}P G A \\
\left(\mathrm{~cm} / \mathrm{s}^{2}\right)\end{array}$ & $\begin{array}{c}P G V \\
(\mathrm{~cm} / \mathrm{s})\end{array}$ & $\begin{array}{c}P G D \\
(\mathrm{~cm})\end{array}$ & $\begin{array}{c}I_{A} \\
(\mathrm{~cm} / \mathrm{s})\end{array}$ & $\begin{array}{c}t_{5-95} \\
(\mathrm{~s})\end{array}$ & $\begin{array}{c}t_{10-90} \\
(\mathrm{~s})\end{array}$ \\
\hline \multirow{2}{*}{ AMT } & NS & 183.48 & 20.48 & 4.26 & 17.79 & 3.18 & 1.43 \\
& EW & 424.98 & 21.52 & 1.54 & 46.23 & 3.75 & 1.13 \\
& $\mathrm{UP}$ & 194.04 & 16.72 & 4.46 & 13.96 & 4.86 & 2.53 \\
& $\mathrm{RES}$ & 425.00 & 22.37 & 4.26 & 64.02 & 3.73 & 1.28 \\
$\mathrm{NRC}$ & $\mathrm{NS}$ & 366.25 & 23.70 & 6.62 & 82.618 & 6.24 & 3.30 \\
& $\mathrm{EW}$ & 352.57 & 29.75 & 5.33 & 104.41 & 6.00 & 4.31 \\
& $\mathrm{UP}$ & 211.48 & 11.59 & 3.04 & 37.87 & 5.52 & 3.74 \\
& $\mathrm{RES}$ & 443.68 & 30.21 & 8.19 & 187.02 & 6.04 & 3.65 \\
\hline
\end{tabular}

Table 1 reports, for each component (NS, EW and UP) and for the resultant of the horizontal components $\left(\mathrm{RES}_{\mathrm{H}}\right)$, the peak values of acceleration (PGA), velocity (PGV) and displacement (PGD) of the recorded ground motions at the selected sites together with the Arias intensity (IA) and the significant duration. The significant duration $\mathrm{t}_{5-95}$ represents the time interval between the point where the Arias intensity reaches the 5\% and $95 \%$ of its maximum value, whereas $t_{10-90}$ is calculated between $10 \%$ and $90 \%$ of Arias intensity. As it is well known, Arias intensity is an index of the energy content of the earthquake, so $t_{5-95}$ and $t_{10-90}$ represent the time in which the earthquake released respectively $90 \%$ and $80 \%$ of its energy. The Arias intensity is considered here because it 
is needed to evaluate the significant duration of the earthquake. Other indices (e.g. input energy) have not been taken into consideration since to judge their significance it would be necessary to conduct a comparison with their values associated to other earthquakes occurred in the past and this is beyond the scope of this work.

From an analysis of the values of Table 1 it can be concluded that the strong motion duration was relatively short and the $90 \%$ of energy was released in about $4 \mathrm{~s}$ in the town of Amatrice and 6 seconds in the town of Norcia. Moreover, the $80 \%$ of energy was released in about $1.5 \mathrm{~s}$ in Amatrice and $3.5 \mathrm{~s}$ in Norcia. To better evidence this behaviour, in Figure 15 the trend of Arias and ground acceleration over the time is shown. This aspect suggests that the nature of the ground motion recorded at the two sites is pulse-like, being controlled by source effects (i.e. directivity and fling-step). This results in a limited cyclic effort for the structures, mainly concentrated in the short periods range (as shown in Figure 14) and can explain why RC buildings suffered less damage than masonry buildings.

Figure 15 Trend of Arias intensity over time and recorded accelerograms (ground acceleration $\mathrm{a}_{\mathrm{g}}$ for NS and EW components) for (a) Amatrice and (b) Norcia

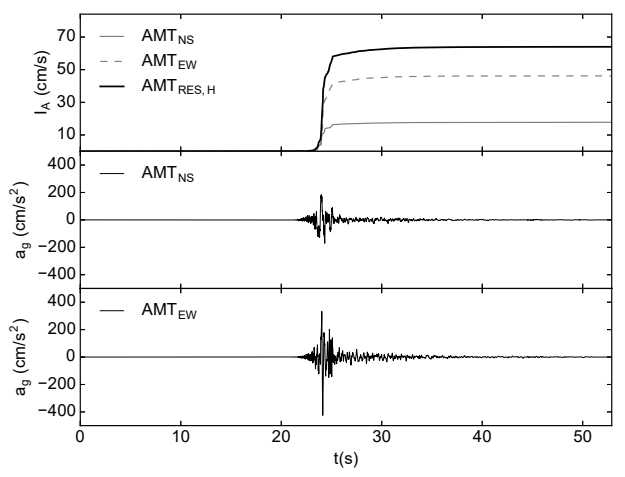

(a)

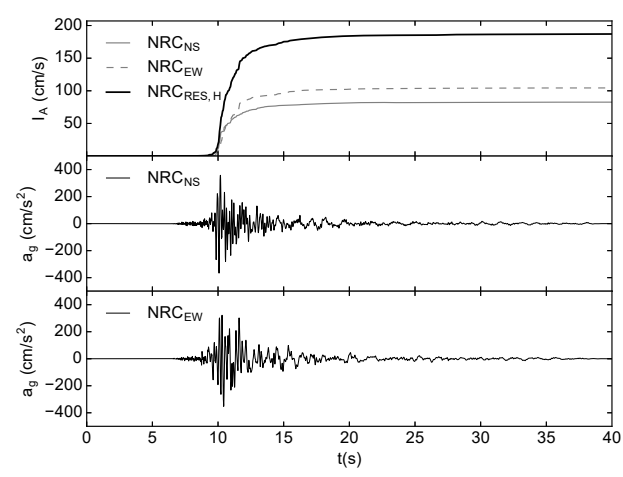

(b)

As far as the masonry structures are concerned, the out-of-plane failure was the most frequent in particular in the towns of Amatrice and Accumoli whereas the town of Norcia was less damaged and showed a better out-of-plane and in-plane behaviour in comparison with the other towns.

The main reason why Norcia exhibited a better out-of-plane behaviour is the presence in the buildings of elements that have prevented the out-of-plane overturning of the masonry walls. Without these preventive measures (e.g. steel ties, ring beams and properly connected rigid diaphragms) the masonry would have a lateral resistance of less than $0.1 \mathrm{~g}$.

Regarding the in-plane behaviour, for an easier understanding of the reasons of the different seismic performance of the masonry buildings in the towns of Amatrice and Norcia, Figure 16 shows elastic and inelastic response spectra for the recorded ground motions (EW components), together with the approximated in-plane resistance variability of the masonry panels in terms of spectral acceleration for an inelastic period of vibration of masonry structures assumed to range between $0.25 \mathrm{~s}$ to $0.4 \mathrm{~s}$. 
Figure 16 In-plane resistance variability (in terms of periods and resistances) of masonry walls compared with the elastic $(\mu=1)$ and inelastic (pivot hysteretic model, $\mu=2)$ response spectra for (a) Amatrice and (b) Norcia records (EW component)

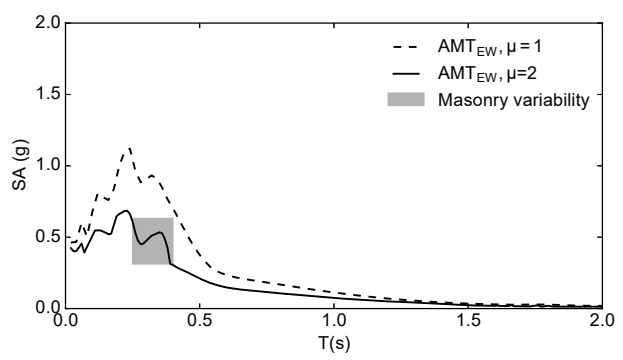

(a)

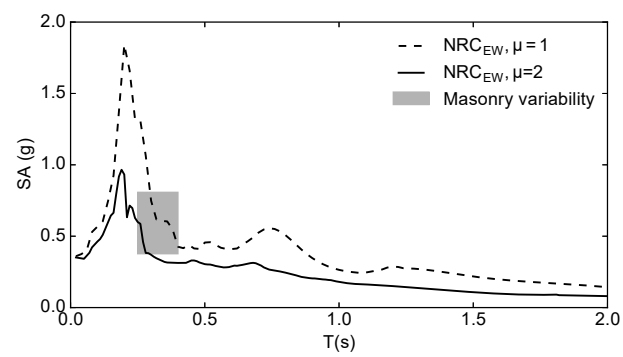

(b)

The inelastic response spectra have been calculated using a ductility $(\mu)$ of 2 and a symmetric Pivot hysteretic model (Dowell et al., 1998) that represents a cyclic behaviour similar to that of a masonry panel where softening, stiffness degradation and pinching effect are very influent in the seismic response (Amadio et al., 2016).

The Pivot parameters assumed are (see Figure 17): $\alpha=1, \beta=0.2$, the elastic stiffness $k_{0}$ varies from period to period, the post elastic stiffness $k_{i}=-0.10 k_{0}$, the yielding strength $F_{y}$ varies from period to period in order to assure $\mu=2$ (typical value of masonry structures). These parameters have been chosen in order to have high cyclic degradation as typical for masonry stones panels.

The resistance of the masonry panels has been roughly calculated considering two different geometries for the panel: height $h$ equal to 6 or 3 metres (i.e. hypothesis of weak or rigid spandrels for a 'standard' two storeys building), length $b$ equal to 2.5 metres (typical distance between two consecutive windows) and a thickness $t$ of 0.6 metres. The weight of the floor has been assumed $12.5 \mathrm{kN} / \mathrm{m}$ (area of influence of about 12 square metres).

Figure 17 Characterisation of the (a) symmetric Pivot hysteretic model (modified from Rinaldin et al., 2016) and (b) cyclic behaviour of a $\mathrm{T}=0.3 \mathrm{~s}$ SDOF model subjected to the Norcia record (EW component, Pivot hysteretic model, $\mu=2$ )

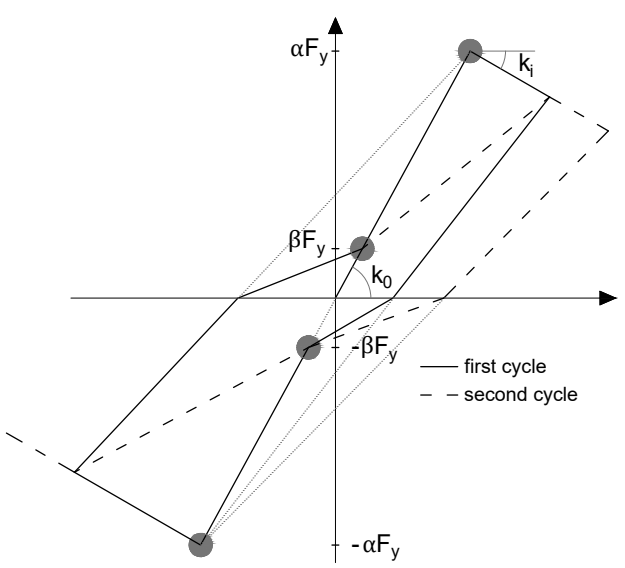

(a)

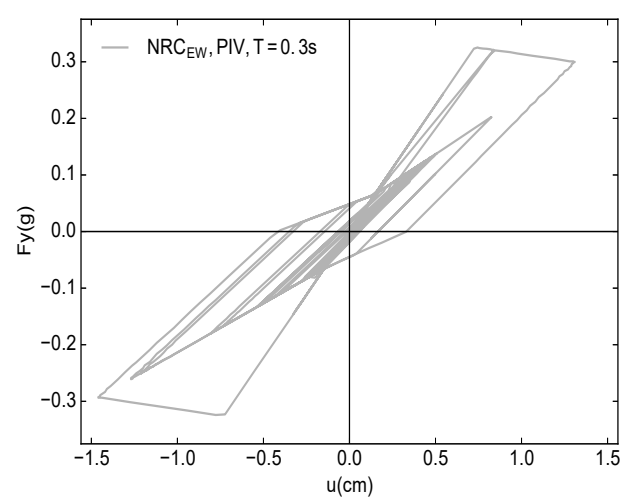

(b) 
Accordingly with the second Newton's law of motion, for each geometry, the qualitative maximum spectral acceleration $S A_{p, R}$ that the panel can withstand is assumed to be the minimum between its shear resistance forces for unitary mass, i.e.:

$$
S A_{p, R}=\min \left(\frac{V_{p, s}}{M} ; \frac{V_{p, r}}{M}\right)
$$

where $V_{p, s}$ represents the shear resistance force associated with diagonal cracking, $V_{p, r}$ the shear resistance force associated with flexural failure (rocking) and $M$ is the mass of the panel. The resistance associated with shear sliding was neglected since it was systematically higher than those considered.

The shear resistance forces have been calculated with the relations reported in NTC08 avoiding safety factors:

$$
\begin{gathered}
V_{p, s}=\frac{b \cdot t \cdot 1.5 \tau_{0}}{\xi} \sqrt{1+\frac{N_{p}}{b \cdot t \cdot 1.5 \tau_{0}}} \\
V_{p, r}=\frac{N_{p} \cdot b}{2 h_{0}}\left(1-\frac{N_{p}}{k \cdot b \cdot t \cdot f_{m}}\right)
\end{gathered}
$$

where $N_{p}$ is the vertical load of the panel, $\xi=h / b$ is a shape factor dependent on the slenderness of the panel $(1 \leq \xi \leq 1.5), h_{0}$ is the shear length of the masonry panel (supposed to be $h_{0}=h / 2$ ), $k=0.85$ is the stress block coefficient, $\tau_{0}$ is the shear strength and $f_{m}$ is the compressive strength. The resistances have been chosen equal to the minimum values suggested by the NTC08 for an existing rubble masonry. In particular, the shear resistance $\tau_{0}$ has been set equal to $20 \mathrm{kN} / \mathrm{m}^{2}$ and the compressive strength $f_{m}$ to $1,000 \mathrm{kN} / \mathrm{m}^{2}$ as it is done in the Italian building code. For the town of Norcia, we assume an improvement in the quality of the masonry due to mortar injections. Following the Italian building code suggestions, this kind of intervention leads to an improvement of the resistances (both shear $\tau_{0}$ and compressive strength $f_{m}$ ) by a factor of 2 . This improvement in the resistances can be assumed since Norcia underwent an extensive retrofit of the buildings after the 1997 Umbria-Marche earthquake and mortar injections have been a widespread intervention.

Figure 16 shows the results of this simplified procedure; the grey box encompasses the approximate variation of the masonry stock in terms of period of vibration and spectral acceleration strength. As it can be seen, in the town of Amatrice the combination ground motion characteristics-masonry resistance was such to undermine the load-bearing structures (grey area below the nonlinear spectrum); this did not happen in the town of Norcia (where the grey area below the nonlinear spectrum is very limited). Moreover, identifying the seismic demand for the masonry buildings as the acceleration spectrum intensity (ASI) of the inelastic response spectrum (i.e. the area below the inelastic response spectrum) in the range of periods between $0.25 \mathrm{~s}$ to $0.4 \mathrm{~s}$, it can be concluded that the demand in the town of Amatrice was higher than that in the town of Norcia. 
Therefore, the good performance of the housing stock in Norcia with respect to Amatrice seems to be due to a combination of structural upgrading (higher resistance, steel ties, ring beams) and ground motion characteristics (lower inelastic acceleration spectral intensity over the standard vibration periods of masonry structures).

The resistance accelerations shown in Figure 16 may also have been influenced by the vertical component of the ground motion that was strong (about $0.5 \mathrm{~g}$ ) precisely in the typical vertical frequencies of the masonry buildings. The lateral resistance may have been reduced by $30 \%-40 \%$ due to the vertical component.

A simple numerical comparison between the values of spectral accelerations used in the design of new buildings and the records (Figure 8) allows us to state that the new buildings, in the places affected by the Central Italy earthquake, are designed to withstand lateral loads lower than those occurred in the last earthquake (at least in the range of periods of masonry structures), not necessarily the largest possible: this earthquake prone area experienced other destructive earthquakes in the past, including the M6.2 Monti della Laga earthquake in 1639 and the large M6.9 Valnerina earthquake in 1703 (e.g. Rovida et al., 2016).

Moreover, it has to be stressed that the occurred earthquake did not reach the worst possible scenario in the area, as it has been demonstrated in Section 3 (see Figure 8). As an example, let us select from the MDSI $_{\text {SS }}$ response spectrum of Norcia (see Figure 18) the NDSHA accelerograms that give a value of the spectral acceleration at the period of $0.3 \mathrm{~s}$ corresponding to the 95th and 50th percentile of the values of all the performed simulations. The 95th percentile can be considered the spectral MCE for a linear structure having a vibration period of $0.3 \mathrm{~s}$; in fact, this aspect shows that one cannot speak of spectral MCE in an absolute sense but only referring to a specific structure. Figure 18 shows the linear and nonlinear $(\mu=2)$ response spectra for the selected ground motions: these scenarios could cause serious damage to the masonry heritage even in the city of Norcia.

Figure 18 In-plane resistance variability of masonry walls compared with the elastic $(\mu=1)$ and inelastic (pivot hysteretic model, $\mu=2$ ) response spectra obtained from the EW accelerograms corresponding to the (a) 50th and (b) 95 th percentile of MDSI $I_{S S}$ for period $\mathrm{T}=0.3 \mathrm{~s}$ in the town of Norcia

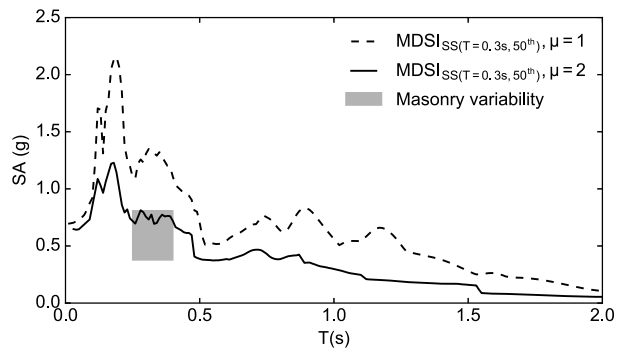

(a)

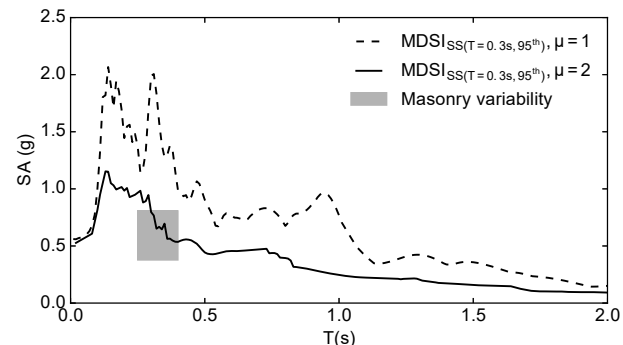

(b) 


\section{Conclusions}

From the damage reports and the engineering considerations we can conclude that in general:

- The damage has been caused by the high seismic vulnerability of the built environment combined with source (i.e. directivity and fling-step) and site effects.

- Masonry structures suffered out-of-plane failures due to a lack of steel ties, ring beams and properly connected rigid diaphragms, and in-plane failures due mainly to poor materials quality.

- Damage to RC buildings mainly due to lack of seismic construction details such as stirrups spacing or the application of the weak beam-strong column criterion. As a rule, they performed better then masonry structures due the ground motion characteristics (e.g. frequency content, limited cyclic effort).

- There is a need for an immediate retrofit of similar structures located in areas characterised by comparable seismic potential.

- It is important to design with appropriate spectral acceleration levels compatible with the possible future scenarios. A feasible approach is provided by the MDSI procedure that does not require the use of the concepts of reference average life and return period.

\section{Note added during revision after the 30th October earthquake $(\mathrm{Mw}=6.5)$}

This article was submitted to the International Journal of Impact and Earthquake Engineering for the peer-review process on October 26, 2016. On October 30, 2016 at 06:40 (UTC) the strongest shock, so far, in the sequence started on August 24, 2016 hit the same area in Central Italy. More precisely, the epicenter of this 6.5 moment magnitude event $(\mathrm{Mw}=6.5)$ is located in the Umbria region, between the towns of Norcia, Preci and Castelsantangelo sul Nera. The earthquake caused serious damage to the built environment in the epicentral area and human losses were averted only because most of the buildings had already been evacuated due to the warnings given by previous shocks.

The October 30 event has dramatically, but fortunately not tragically, confirmed the conclusion contained in the original version of this paper. It is therefore appropriate to enrich the comparison shown in Figure 8 and to add the spectral acceleration recorded during the $\mathrm{Mw}=6.5$ event at the same station (Norcia $-\mathrm{NRC}$ ). The comparison is shown in Figure 19. As it can be seen, the spectral acceleration for the October $30 \mathrm{Mw}=6.5$ event, whose magnitude is close to the maximum ever observed in the area, are in very good agreement with what we proposed as MDSI. This fact evidences the robustness of the process behind the computation of the MDSI, based on NDSHA ground motion simulations, and confirms that it can be used as a code seismic input, in order to design using appropriate spectral accelerations consistent with the seismic potential of a prefixed area. 
Figure 19 Comparison between observed SA at NRC station (events of 24/08/2016 and 30/10/2016), NTC08 spectrum for soil B at the same site (dark lines) and local

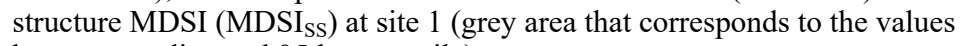
between median and 95 th percentile)

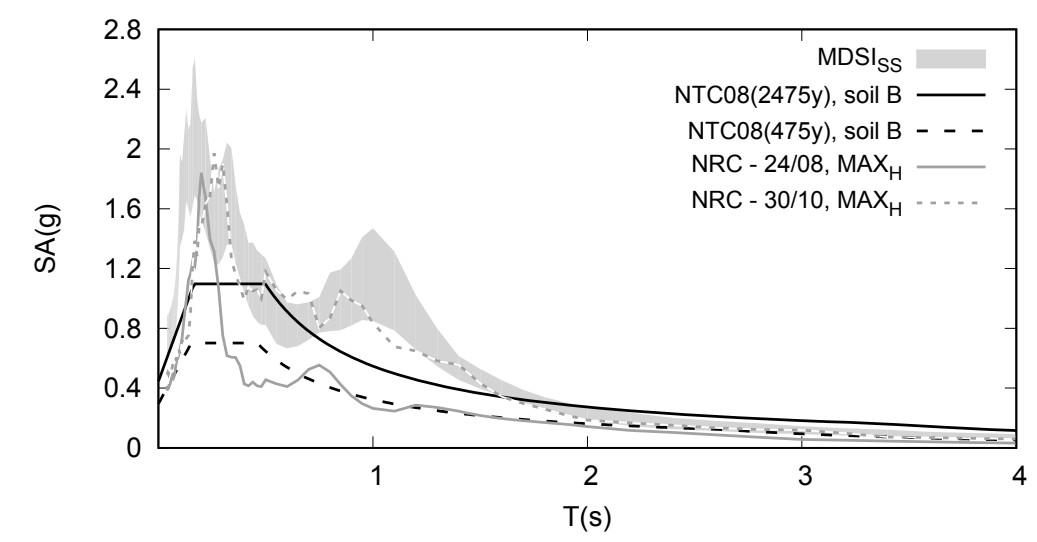

\section{Acknowledgements}

We thank Eng. Antonio Colussi and Eng. Egisto Morson for giving us the original photos shown in Figures 9, 10 and 11. We thank Dr. Giovanni Rinaldin for having made available the Pivot software used in Section 4. Some of the results shown in this work have been obtained within the framework of National agreements. In particular, we acknowledge the partial support of the Veneto Regional Secretariat of the Italian Ministry of Cultural Heritage and Activities and Tourism (MiBACT), the Fondazione Cassa di Risparmio di Gorizia and Funds for Cooperation and Development LR 19/2000 - Friuli Venezia Giulia Region (call 2016).

\section{References}

Amadio, C., Rinaldin, G. and Fragiacomo, G. (2016) 'Investigation on the accuracy of the N2 method and the equivalent linearization procedure for different hysteretic models', Soil Dynamics and Earthquake Engineering, Vol. 83, pp.69-80, DOI: 10.1016/j.soildyn.2016. 01.005 .

ASCE (2013) ASCE Standard ASCE/SEI 41-13: Seismic Evaluation and Retrofit of Existing Buildings, American Society of Civil Engineers, Reston, Virginia.

Bindi, D., Luzi, L., Parolai, S., Di Giacomo, D. and Monachesi, G. (2011) 'Site effects observed in alluvial basins: the case of Norcia (Central Italy)', Bull. Earthquake Eng., Vol. 9, No. 6, pp.1941-1959, DOI: 10.1007/s10518-011-9273-3.

Bohm, G., Luzi, L. and Galadini, F. (2011) 'Tomographic depth seismic velocity model below the plain of Norcia (Italy) for site effect studies', Bollettino di geofisica Teorica ed Applicata, Vol. 52, No. 2, pp.197-209.

Boore, D.M. (1986) 'The effect of finite bandwidth on seismic scaling relationships', in S. Das, J. Boatwright and C.H. Scholz (Eds.): Earthquake Source Mechanics, pp.275-283, doi: 10.1029/GM037p0275, American Geophysical Union, Washington, DC. 
Brandmayr, E., Raykova, R.B., Zuri, M., Romanelli, F., Doglioni, C. and Panza, G.F. (2010) 'The lithosphere in Italy: structure and seismicity', Journal of the Virtual Explorer, Vol. 36, DOI: $10.3809 /$ jvirtex.2009.00224.

Caputo, M., Keilis-Borok, V., Kronrod, T., Molchan, G., Panza, G.F., Piva, A., Podgaezkaya, V. and Postpischl, D. (1973) 'Models of earthquake occurrence and isoseismals in Italy', Ann. Geofis., Vol. 26, Nos. 2-3, pp.421-444.

D’Amico, V., Albarello, D. and Mantovani, E. (1999) 'A distribution-free analysis of magnitudeintensity relationships: an application to the Mediterranean region', Physics and Chemistry of the Earth, Part A: Solid Earth and Geodesy, Vol. 24, No. 6, pp.517-521.

D'Ayala, D.F. and Paganoni, S. (2011) 'Assessment and analysis of damage in L'Aquila historic city centre after 6th April 2009', Bull Earthquake Eng., Vol. 9, No. 1, pp.81-104, DOI $10.1007 / \mathrm{s} 10518-010-9224-4$.

Doglioni, C. (2016) 'Plate tectonics, earthquakes and seismic hazard', Resilienza delle città d'arte ai terremoti, Accademia Nazionale dei Lincei, Roma, Italy, in press.

Dowell, R.K., Frieder, S. and Wilson, L.E. (1998) 'Pivot hysteresis model for reinforced concrete members', ACI Structural Journal, Vol. 95, No. 5, pp.607-617.

Fasan, M., Amadio, C., Noè, S., Panza, G.F., Magrin, A., Romanelli, F. and Vaccari, F. (2015) 'A new design strategy based on a deterministic definition of the seismic input to overcome the limits of design procedures based on probabilistic approaches', XVI ANIDIS Conference, L'Aquila, Italy.

Fasan, M., Magrin, A., Amadio, C., Panza, G.F., Romanelli, F., Vaccari, F. and Noè, S. (2017) 'A possible revision of the current seismic design process', 16th World Conference on Earthquake Engineering, 16WCEE 2017, Santiago Chile.

Gasperini, P., Camassi, R., Mirto, C. and Stucchi, M. (2004) Catalogo Parametrico dei Terremoti Italiani, versione 2004 (CPTI04), INGV, Bologna.

Gorshkov, A., Panza, G.F., Soloviev, A.A. and Aoudia, A. (2002) 'Morphostructural zonation and preliminary recognition of seismogenic nodes around the Adria margin in peninsular Italy and Sicily', Journal of Seismology and Earthquake Engineering, Vol. 4, No. 1, pp.1-24.

Gorshkov, A.I., Panza, G.F., Soloviev, A.A. and Aoudia, A. (2004) 'Identification of seismogenic nodes in the Alps and Dinarides', Bollettino della Societa Geologica Italiana, Vol. 123, No. 1, pp.3-18.

Gorshkov, A.I., Panza, G.F., Soloviev, A.A., Aoudia, A. and Peresan, A. (2009) 'Delineation of the geometry of the nodes in the Alps-Dinarides hinge zone and recognition of seismogenic nodes (M $\geq 6$ )', Terra Nova, Vol. 21, No. 4, pp.257-264, doi: 10.1111/j.1365-3121.2009.00879.x.

Gusev, A.A. (1983) 'Descriptive statistical model of earthquake source radiation and its application to an estimation of short-period strong motion', Geophysical Journal of the Royal Astronomical Society, Vol. 74, No. 3, pp.787-808.

Gusev, A.A. (2011) 'Broadband kinematic stochastic simulation of an earthquake source: a refined procedure for application in seismic hazard studies', Pure and Applied Geophysics, Vol. 168, No. 1, pp.155-200.

INGV (2016) Secondo rapporto di sintesi sul Terremoto di Amatrice Ml 6.0 del 24 Agosto 2016 (Italia Centrale), Gruppo di Lavoro INGV sul terremoto di Amatrice, doi: 10.5281/ zenodo. 154400 .

Keilis-Borok, V.I. and Soloviev, A.A. (Eds.) (2003) Non-linear Dynamics of the Lithosphere and Earthquake Prediction, 337pp, Springer, Heidelberg.

Magrin, A., Gusev, A., Romanelli, F., Vaccari, F. and Panza, G.F. (2016) 'Broadband NDSHA computations and earthquake ground motion observations for the Italian territory', Int. J. Earthquake and Impact Engineering, Vol. 1, Nos. 1/2, pp.131-158.

Markušić, S., Suhadolc, P., Herak, M. and Vaccari, F. (2000) 'Contribution to seismic hazard assessment in Croatia from deterministic modeling', Pure and Applied Geophysics, Vol. 157, Nos. 1-2, pp.185-204. 
Meletti, C. and Valensise, G. (2004) 'Zonazione sismogenetica ZS9 - App.2 al Rapporto Conclusivo', in Gruppo di Lavoro, M.P.S. (Ed.): Redazione della mappa di pericolosit a sismica prevista dall'Ordinanza PCM 3274 del 20 marzo 2003, Rapporto Conclusivo per il Dipartimento della Protezione Civile, Milano-Roma: INGV. aprile 2004, 65pp, +5 enclosures.

Molchan, G., Kronrod, T. and Panza, G.F. (1997) 'Multi-scale seismicity model for seismic risk', Bulletin of the Seismological Society of America, Vol. 870, No. 5, pp.1220-1229.

NTC08 (2008) D.M. 14 gennaio 2008 - Norme tecniche per le costruzioni (in Italian), Ministero delle Infrastrutture [online] http://www.cslp.it.

Panza G.F., Kossobokov, V., Peresan, A. and Nekrasova, A. (2014) 'Why are the standard probabilistic methods of estimating seismic hazard and risks too often wrong', in M. Wyss (Ed.): Earthquake Hazard, Risk and Disasters, pp.309-357, doi: 10.1016/B978-0-12-3948489.00012-2, Elsevier, Waltham, Massachusetts.

Panza, G.F., La Mura, C., Peresan, A., Romanelli, F. and Vaccari, F. (2012) 'Seismic hazard scenarios as preventive tools for a disaster resilient society', Advances in Geophysics, Vol. 53, pp.93-165.

Panza, G.F., Romanelli, F. and Vaccari, F. (2001) 'Seismic wave propagation in laterally heterogeneous anelastic media: theory and applications to seismic zonation', Advances in Geophysics, Vol. 43, pp.1-95.

Parvez, I.A., Romanelli, F. and Panza, G.F. (2011) 'Long period ground motion at bedrock level in Delhi city from Himalayan earthquake scenarios', Pure and Applied Geophysics, Vol. 168, Nos. 3/4, pp.409-477.

Pavlov, V.M. (2009) 'Matrix impedance in the problem of the calculation of synthetic seismograms for a layered-homogeneous isotropic elastic medium', Izvestiya Physics of the Solid Earth, Vol. 45, No. 10, pp.850-860.

Peresan, A., Kossobokov, V., Romashkova, L. and Panza, G.F. (2005) 'Intermediate-term middlerange earthquake predictions in Italy: a review', Earth-Science Reviews, Vol. 69, No. 1, pp.97-132.

Peresan, A., Kossobokov, V., Romashkova, L., Magrin, A., Soloviev, A.A. and Panza, G.F. (2016) 'Time-dependent neo-deterministic seismic hazard scenarios: preliminary report on the M6.2 Central Italy earthquake, 24th August 2016', New Concepts in Global Tectonics Journal, Vol. 4, No. 3, pp.487-493.

ReLUIS (2016) Rapporto fotografico relativo ai danni subiti da alcuni edifici a seguito del sisma del centro Italia del 2016 [online] http://www.reluis.it (accessed 01/10/2016).

ReLUIS-INGV Workgroup (2016) Preliminary Study of Rieti Earthquake Ground Motion Records V5 [online] http://www.reluis.it (accessed 01/10/2016).

Ricci, P., De Luca, F. and Verderame, G.M. (2011) '6th April 2009 L'Aquila earthquake, Italy: reinforced concrete building performance', Bull. Earthquake Eng., Vol. 9, No. 1, pp.285-305, DOI 10.1007/s10518-010-9204-8.

Rinaldin, G., Amadio, C. and Fragiacomo, M. (2016) 'Effects of seismic sequences on structures with hysteretic or damped dissipative behaviour', submitted to Soil Dynamics and Earthquake Engineering.

Rovida, A., Locati, M., Camassi, R., Lolli, B. and Gasperini, P. (Eds.) (2016) CPTI15, the 2015 version of the Parametric Catalogue of Italian Earthquakes, Istituto Nazionale di Geofisica $\mathrm{e}$ Vulcanologia, doi:http://doi.org/10.6092/INGV.IT-CPTI15.

Tinti, E., Scognamiglio, L. Michelini, A. and Cocco, M. (2016) 'Slip heterogeneity and directivity of the $\mathrm{M}_{\mathrm{L}}$ 6.0, 2016, Amatrice earthquake estimated with rapid finite-fault inversion', Geophys. Res. Lett., Vol. 43, No. 20, pp.10745-10752, doi: 10.1002/ 2016GL071263.

USGS (2016) Report on the Central Italy Earthquake of 24 August 2016 - Magnitude 6.2 [online] $\mathrm{http} / / /$ earthquake.usgs.gov/earthquakes/eventpage/us10006g7d\#general_summary (accessed 01/10/2016).

Živčić, M., Suhadolc, P. and Vaccari, F. (2000) 'Seismic zoning of Slovenia based on deterministic hazard computations', Pure and Applied Geophysics, Vol. 157, Nos. 1-2, pp.171-184. 


\section{Notes}

1 Accordingly to PSHA, the 'return period' is one over the annual rate at which a ground motion level is exceeded at a site and should not be confused with the 'recurrence interval', i.e. the average time interval between the occurrence of two equal (within errors) magnitude earthquakes in a given seismogenic zone. The 'return period' is computed from frequency magnitude-relations, GMPE and distribution of sources and therefore it is based on earthquake recurrence estimations, i.e. on the inter-event time for a given zone that, mainly for strong events, is sporadic and often unknown. For this reason 'return period' is used within quotes.

2 The range 0.2 represents a lower limit value for the standard deviation with which magnitudes are globally determined. 